IZA DP No. 7792

Jailer of Freedom and Enemy of Growth? The Role of Personal and Social Identities in Educational Choices

Giuseppina Autiero

Niall O’Higgins

December 2013 


\title{
Jailer of Freedom and Enemy of Growth? The Role of Personal and Social Identities in Educational Choices
}

\author{
Giuseppina Autiero \\ University of Salerno \\ Niall O'Higgins \\ University of Salerno \\ and IZA
}

\section{Discussion Paper No. 7792 \\ December 2013}

\author{
IZA \\ P.O. Box 7240 \\ 53072 Bonn \\ Germany \\ Phone: +49-228-3894-0 \\ Fax: +49-228-3894-180 \\ E-mail: iza@iza.org
}

Any opinions expressed here are those of the author(s) and not those of IZA. Research published in this series may include views on policy, but the institute itself takes no institutional policy positions. The IZA research network is committed to the IZA Guiding Principles of Research Integrity.

The Institute for the Study of Labor (IZA) in Bonn is a local and virtual international research center and a place of communication between science, politics and business. IZA is an independent nonprofit organization supported by Deutsche Post Foundation. The center is associated with the University of Bonn and offers a stimulating research environment through its international network, workshops and conferences, data service, project support, research visits and doctoral program. IZA engages in (i) original and internationally competitive research in all fields of labor economics, (ii) development of policy concepts, and (iii) dissemination of research results and concepts to the interested public.

IZA Discussion Papers often represent preliminary work and are circulated to encourage discussion. Citation of such a paper should account for its provisional character. A revised version may be available directly from the author. 


\begin{abstract}
Jailer of Freedom and Enemy of Growth?* The Role of Personal and Social Identities in Educational Choices

This paper develops a theoretical and empirical model on the influence of identity on educational choices which extends the existing literature in several directions. The theoretical model proposed here allows schooling choices to be independently influenced by both personal and social identities and, in contrast to previous work, the proposed empirical counterpart is derived directly from the theoretical model. The use of UK's British Cohort Study on individuals born in 1970 allows us to identify with precision the relevant explanatory factors and to appropriately control for potentially confounding factors. Both social and personal identities are found to have substantial and statistically significant effects on educational participation decisions and these impacts are robust to a variety of specifications. The key implication is that socio-psychological factors play an important role in children's school performance through their direct influence on the utility derived from studying.
\end{abstract}

JEL Classification: D01, I21, J24

Keywords: identity, educational choice, locus of control

Corresponding author:

Niall O'Higgins

Department of Economics and Statistics

University of Salerno

Via Giovanni Paolo II

132-84084 Fisciano (SA)

Italy

E-mail: nohiggins@unisa.it

\footnotetext{
* The quote is taken from a speech made by John Franklin Kennedy in 1961, the full sentence reads,

"Conformity is the jailer of freedom and the enemy of growth."
} 


\section{Introduction}

In recent years, the role of identity in motivating individual choices has increasingly been recognised in economists' models of individual choice due, in no small part, to the seminal contributions of Akerlof and Kranton (2000, 2002, 2005). Here, taking Akerlof and Kranton's (2000) model of educational choice as a starting point, drawing also on the relevant economic, psychological and sociological literature, we develop a theoretical model and derive and estimate its empirical counterpart analysing the role of identity in determining schooling choice. The paper extends the existing literature in a number of ways. First, the theoretical model presented here allows schooling choices to be influenced independently by both personal and social identity; second, the empirical counterpart to the theoretical model is derived directly from the latter rather than being some general approximation with ad hoc additions as is more commonly employed; and, third, the use of a long and rich longitudinal panel allows us to identify precisely the relevant explanatory factors and to appropriately control for potentially confounding factors. The results confirm the important role played by personal and social identity in determining schooling choices and we find that their impact is robust to the inclusion of a variety of potentially confounding explanatory factors.

Akerlof and Kranton (2000), drawing on the psychology and sociology literature, have attracted economists' attention to the role of identity as a key-factor in motivating individual choices. Generally social identity and sense of self are bound to the social categories and groups to which individuals belong. People internalize and share the norms underlying the behaviour prescribed in particular situations by their social category (Akerlof, Kranton, 2005). Identifying with a specific social category and adhering to its consequent behavioural prescriptions affects individuals' utility by enhancing their sense of self; in contrast, not complying with the prescribed behaviour may cause a certain discomfort and a reduction in their utility. Of relevance here, Akerlof and Kranton (2002) argue that identity can inter alia 
motivate school effort. In their view, students may be part of a school category like jocks, nerds and burnouts at high school, which defines their self-image.

However, a glance at the relevant psychology literature suggests a broader view; in particular, individual identity may usefully be seen as a two - dimensional concept embracing not only aspects of social identity but also those of personal identity. The latter corresponds to the notion of 'inner identity' and is moulded by unique individual characteristics less permeable than social identity to outside influence (Jones and McEwen, 2000). Personal identity is defined as a combination of self-concept and beliefs of self-efficacy related to cognition of oneself, self-esteem characterised by the emotional evaluation of self-worth and locus of control affecting individual motivations (Haußer, 1995), all features which mould individual dispositional traits (Judge and Bono, 2001). The concept of the locus of control as a motivational feature of personal identity concerns the extent to which an individual believes that her own actions or characteristics influence outcomes. For persons with an external locus, outcomes are deemed to be affected by chance or fate and are beyond their control (Rotter, 1966). In the case of education, effort and hard work are not believed to improve academic achievements, which are rather ascribed to luck.

Recently, analyses looking at the role of locus of control in determining economic agents' decisions have become more widespread in the economics literature. Of direct relevance to our analysis, Coleman and DeLeire (2003) build a human capital investment model where locus of control influences educational choices through its effects on the perceived probability of success in the labour market. Individuals with an internal locus believe that if they graduate from high school, they will receive a higher premium compared to not graduating; whereas, individuals with an external locus do not expect graduation from high school to greatly affect their labour market performance. Thus, the probability of graduation is influenced by an individual's locus of control. The authors present empirical evidence which supports their analytical results. The importance of non cognitive abilities and, in particular, personal traits such as internal locus in human capital investments has been found by a number of other 
studies (Heckman et al. 2006; Baròn and Cobb-Clark, 2010). Bowles et al. (2001) show how, in a contractually incomplete employer-employee relationship, what they call incentiveenhancing preferences can play a crucial role in determining work effort. The factors characterising incentive-enhancing preferences are personal traits and, in particular, locus of control. Fatalistic workers with external loci exert less effort at work because they believe that their actions will have a smaller influence on the probability of job termination than do internal workers. Indeed, Osborne (2005) empirically verifies such an influence of locus of control - amongst other psychological traits - on women's wages taking into account also standard human capital variables. Andrisani (1977) shows empirically that internal attitudes translate into individual labour market success. For instance, internal locus and the consequent awareness that success depends on individual initiative, lead to better market experiences for both white and black young men in terms of growth of earnings and career advancement. It is worth stressing that locus of control and self-esteem - two aspects of personal identities are linked in as much as individuals with high self-esteem tend to ascribe successful results of their actions to their internal locus rather than to external circumstances and luck (Abdallah, 1989). Yet from a psychological perspective, since self-esteem comprises a heterogeneous set of characteristics ranging from self-acceptance of one's qualities to narcissist or defensive attitudes, high self-esteem does not necessarily influence school and job performance (Baumeister et al., 2003). Thus, it is locus of control rather than self-esteem which is the more appropriate feature to utilise in order to capture the motivational aspects of individual choices. The relationship between social identity and locus of control has also been the subject of study in the empirical literature. Pearlin and Kohn (1966) consider social class as social identity and emphasize that middle class parents stimulate self-determination and selfdirection boosting children's locus of control, whereas working class parents induce the acceptance of the existing status imposed by external conditions. Whereas when parents' occupational status is identified as social identity, the evidence shows that locus of control and parents' occupational status independently affect children's educational and occupational 
achievements and that there is no correlation between locus of control and parents' social status (Wang at al.,1999; Von Stumm et al., 2009). In the light of these contributions, social identity captured by family socio-economic background and locus of control as a component of personal identity seem not to be characterised by a clear-cut causal link. Thus, there appear to be grounds to consider personal identity - in the form of locus of control - and social identity - in the form of family background - as separate determinants of children's behaviour.

In this paper, we build a theoretical model of young people's scholastic effort which takes into account the role that both personal identity and social identity play in decision-making, drawing on the contributions considered above. In fact, it would be mistaken to ignore the crucial role that both social and personal identity play in motivating economic choices. The theoretical model presented here is supported by the implementation of an empirical model which is derived directly from it. The empirical analysis makes use of the UK's British Cohort Study, which collects information on individuals born in 1970 and is a rich data set particularly adapted to our purposes. The evidence presented confirms the predictions of the theoretical model and the variables identifying social and personal identities are robust to several specification checks.

In the next section, we develop a model in which children's social and personal identity separately influence the utility of effort exerted at school. In section 3, we derive the empirical model and describe the data set and the explanatory variables employed. Section 4 presents the core results and then proceeds to implement a series of robustness checks. This is followed by some concluding remarks summarising our findings.

\section{Social and personal identity in a simple model of school effort choice}

Our theoretical model draws on the contribution of Akerlof and Kranton (2002) and analyzes the influence of individual identity on school effort. We broaden their model by introducing an explicit distinction between social and personal identity. Personal identity is defined in 
terms of the degree of a person's internal locus. As specified in the introduction, an internal locus believes that her actions will affect outcomes. Another point of difference from Akerlof and Kranton (idem) is that while in their analytical framework individuals gain utility from identity per se, in ours, social and personal identity influence the utility derived from scholastic effort. More specifically, individual social identity is shaped by family background; the relation between parents and children implies the transmission of parents' norms and values concerning the importance of school performance and educational achievements (Coleman, 1988). Children's compliance with the behavioural requirements prescribed by such norms and values is driven by the need to conform to parental expectations and is a crucial component of their self-definition (Kelman, 2005). In our model, in a family that transmits values stressing the importance of educational achievements, children may derive utility from school effort as in this way they meet their parents' expectations for their behaviour at school. Locus of control is relevant to scholastic effort in as much as individuals with a sense of competence about their abilities and a stronger feeling of control of success and failure with respect to their own personal goals, are likely to be more motivated at school. Thus, individuals who are either more oriented towards educational achievements or possess more internal locus get greater utility for a given effort level to the extent to which they meet parents' expectations or ascribe academic achievements to their own effort rather than to the external environment.

In addition, in common with Akerlof and Kranton (2002), the match between students' effort and the behavioural standard prescribed by the school attended may also affect utility. If an individual's behaviour is in contrast with the school's model, her utility from effort is reduced. On this basis, the utility function of individual $i$ may be expressed as:

$$
U_{i}\left(e_{i}, I_{B i}, I_{L i}\right)=\alpha\left(e_{i} n_{i}-\frac{1}{2} e_{i}^{2}\right)+(1-\alpha)\left[\left(\beta I_{B i}+\gamma I_{L i}\right) e_{i}-\frac{\vartheta}{2}\left(e_{i}-e(S)\right)^{2}\right]
$$


In [1], $\alpha$ and $(1-\alpha)$ - with $\alpha \geq 0$ - indicate the relative weights of the standard and identity driven components of the utility function. When $\alpha=0$, only the identity part counts while if $\alpha=1$, standard cost/benefit considerations prevail; $e_{i} n_{i}$ represents $i$ 's marketable skill or human capital with $e_{i}$ corresponding to individual effort and $n_{i}$ to individual ability ${ }^{2}$; effort $\operatorname{cost}$ is $\frac{1}{2} e_{i}^{2}$. As to the second addend in square brackets, the first element includes the overall identity component, which affects the utility from school effort. $I_{B}>0$ is individual social identity deriving from family background, which represents the extent to which parents value education with $\beta>0$. If social identity does not count, $\beta=0$. The variable $\mathrm{I}_{\mathrm{L}}>0$ represents the degree of locus of control with higher values of $\mathrm{I}_{\mathrm{L}}$ corresponding to a more internal locus with $\gamma>0$.

The second component in square brackets with $\vartheta \geq 0$ captures the loss in utility due to the divergence of individual effort, $e_{i}$, from the ideal school behaviour $e(S)$ as in this case the individual sense of identity is diminished. When the individual is not affected by the distance of her own behaviour from that prescribed by the school then $\vartheta=0$.

The equilibrium solution is:

$e_{i}^{*}=\frac{1}{\alpha+(1-\alpha) \vartheta}\left[a n_{i}+(1-\alpha)\left(\beta I_{B i}+\gamma I_{L i}\right)+(1-\alpha) \vartheta e(S)\right]$

The influence of identity on effort is shown by the partial derivatives of optimal effort with respect to social and personal identity:

\footnotetext{
2 The complete expression for marketable skills is $w n_{i} e_{i}$ but for simplicity we normalize the wage $w$ to one.
} 


$$
\begin{aligned}
\frac{\partial e_{i}^{*}}{I_{B i}} & =\beta \frac{1-\alpha}{\alpha+\vartheta(1-\alpha)} \\
\frac{\partial e_{i}^{*}}{I_{L i}} & =\gamma \frac{1-\alpha}{\alpha+\vartheta(1-\alpha)}
\end{aligned}
$$

As one would expect in [3] the influence of social identity depends in particular on the size of the parameter $\beta$ and the same occurs with the size of $\gamma$ for locus of control in [4]. These results are quite straightforward and show that if family becomes more pro-school, the effort increase is greater the stronger the influence of social identity on the utility from school effort $(\beta)$. In this respect, parents may be more or less effective in shaping children attitudes towards school depending on their son's inclination to internalize the values transmitted by family. Thus if parents increase their attention to their sons academic achievements and raise their expectations, this pushes up children's effort to an extent indicated by this factor. Analogously if the internal locus of children becomes stronger, it raises school effort. This effect is higher when internal attitudes are more relevant with respect to scholastic effort (higher $\gamma$ ). Moreover, the relative impact of social vs. personal identity depends only on the relative size of $\beta$ and $\gamma$. 


\section{Empirical Model}

The theoretical model outlined above has a natural empirical counterpart which can be straightforwardly implemented. In order to do so we assume that continuing in education beyond a specific educational stage depends only on optimal effort being above a certain level $^{3}$. That is, a young person will decide to continue in education at each stage if optimal effort is greater than or equal to some threshold value.

Thus, we may state that an individual will continue in education beyond the minimum school leaving age of sixteen iff,

$e^{*}>a_{0}$

we may also, adding individual subscripts and a stochastic term, rewrite equation [2] as,

$e_{i}^{*}=b_{1} n_{i}+b_{2} I_{B i}+b_{3} I_{L i}+b_{4} e(S)_{i}-u_{i} \quad u_{i} \sim N(0,1)$

Where $b_{1}=\left(\frac{\alpha}{\alpha+\vartheta(1-\alpha)}\right)$ and so on for the other coefficients.

If we define $s_{i}=1$ iff the individual remains in education beyond age 16 , then equations [5] and [6] lead directly to a probit model. That is,

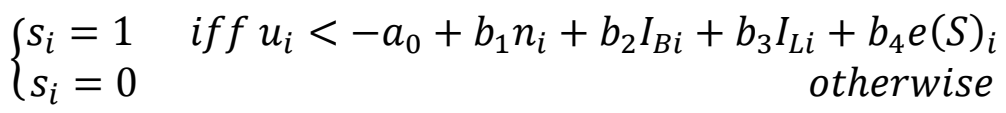

Thus, the probability that an individual stays on in education beyond minimum school leaving age can be expressed as:

$$
\begin{aligned}
p\left(s_{i}=1\right)=p\left(e^{*}>a_{0}\right) & =p\left(u_{i}<-a_{0}+b_{1} n_{i}+b_{2} I_{B i}+b_{3} I_{L i}+b_{4} e(S)_{i}\right) \\
& =\Phi\left(-a_{0}+b_{1} n_{i}+b_{2} I_{B i}+b_{3} I_{L i}+b_{4} e(S)_{i}\right)
\end{aligned}
$$

Where $\Phi($.$) is the cumulative standard normal distribution; in other words, the probit model.$

\footnotetext{
${ }^{3}$ Strictly speaking it would be sufficient (and more realistic) in the stochastic model outlined, to posit that optimal effort is positively correlated with continued participation in school.
} 
Other thresholds at different ages can be added to represent staying on at later points in a young person's life. In this paper we consider also the decision taken at 18 or thereabouts when, assuming they haven't previously left school, the person decides whether to continue on into tertiary education or not. Assuming a static decision framework, this leads to an ordinal probit model with, in our case, school leaving/staying on decisions being made at 16 and 18; a two threshold model. In this case, a person will stay on at 18 , conditional on having remained in education beyond 16 iff,

$e^{*}>a_{1}\left(>a_{0}\right)$

Thus, in this case, we have:

$\mathrm{s}_{\mathrm{i}}=0$ if the person leaves school at $16 ; \mathrm{s}_{\mathrm{i}}=1$ if they leave school at 18 and $\mathrm{s}_{\mathrm{i}}=2$ if they remain in education beyond 18 . Thus,

$\left\{\begin{array}{rlr}s_{i}=0 & \text { if } & e^{*} \leq a_{0} \\ s_{i}=1 & \text { if } & a_{0}<e^{*} \leq a_{1} \\ s_{i}=2 & \text { if } & a_{1}<e^{*}\end{array}\right.$

Or, in other words, the ordered probit model. Thus, in what follows we implement ordered and, for robustness checks, dichotomous probits to estimate the probability of leaving education at different stages in an individual's scholastic career and which, by implication, provide estimates of scholastic effort.

\subsection{Data and Variable definitions}

The variables used in the analysis are all drawn from the UK's British Cohort Study (BCS), a longitudinal study which comprises detailed survey, test and medical information on a group of individuals born in the second week of April 1970. Information has been collected on participants in a series of waves throughout the participants' lives to date; we use data primarily from the sweeps conducted at age 10 and age 26. The BCS is particularly appropriate for our analysis for a number of reasons. The key explanatory variables are 
defined on the basis of observation of individuals at age 10. That is, long before the decision to leave school are taken thus attenuating issues of the endogeneity of the explanatory variables with regard to the school-leaving decisions taken at 16 and 18 . The information collected by the study is also extremely thorough and detailed. Thus, for example, we are able to employ a sixteen item test of locus of control rather than the four item test used by the American studies looking at the relationship between locus of control and educational outcomes ${ }^{4}$. The assessment of ability, using the British Ability Scale is undertaken early, involves a detailed assessment of children's cognitive abilities and is widely accepted and used as a measure of children's cognitive ability ${ }^{5}$.

The principal variables used in the analysis are defined as follows:

School-leaving: $\mathbf{S}_{\mathbf{i}}=0$ if the person leaves school at sixteen (or before), $\mathbf{S}_{\mathbf{i}}=1$ if the person stays on in school at sixteen, but leaves at eighteen and $\mathbf{S}_{\mathbf{i}}=2$ if the persons continues in education beyond age eighteen drawn from information provided by survey participants at age 26 ;

Ability: $\mathbf{n}_{\mathbf{i}}$ is based on each participant's integer score in the so-called 'British ability scale' test undertaken by survey participants at age 10 ;

Social Identity: $\mathbf{I}_{\mathbf{B i}}$ is an index created by combining two variables measuring maternal and paternal interest in their children's education as perceived by the school teacher when the study participant was aged 10. The reason why we have chosen parental interest in child education is that among the other questions in the survey it best represents parental involvement in their children's educational progress.

Personal Identity: $\mathbf{I}_{\mathbf{K i}}$ is based on the score in the Caroloc (Locus of Control) 16 question test undertaken at age 10 ;

\footnotetext{
${ }^{4}$ In particular, Coleman and Deleire (2003) and Cebi (2007).

${ }^{5}$ See, for example, Hill (2005).
} 
School ethos: it captures the ideal school behaviour $\boldsymbol{e}(\boldsymbol{S})$ and is based on the average academic intake estimated by the school principal/head-teacher.

All of the explanatory variables were rescaled so as to take values between 1 and 5 . The purpose was to make the coefficients of the ordered probit model more directly comparable with one another.

Table 1: Descriptive statistics for the core variables

\begin{tabular}{|c|c|c|c|c|c|}
\hline Variable & Brief description & Mean & s.d. & $\min$ & Max \\
\hline \multirow{3}{*}{$\begin{array}{l}\text { School- } \\
\text { leaving/staying }\end{array}$} & Left school at 16 & .594 & - & 0 & 1 \\
\hline & Left school at 18 & .158 & - & 0 & 1 \\
\hline & Stayed in education at 18 & .248 & - & 0 & 1 \\
\hline Ability & British ability scale at age 10 & 3.00 & 0.59 & 1 & 5 \\
\hline Social identity & $\begin{array}{l}\text { Parental interest in child's education at age } \\
10\end{array}$ & 4.07 & 0.89 & 1 & 5 \\
\hline $\begin{array}{l}\text { Personal } \\
\text { Identity }\end{array}$ & Locus of control at age 10 & 3.00 & 0.77 & 1 & 5 \\
\hline School Ethos & $\begin{array}{l}\text { academic intake of school attended at age } \\
10\end{array}$ & 3.06 & 0.35 & 1 & 5 \\
\hline
\end{tabular}

Note: Full descriptive statistics for the additional variables included in the robustness checks are included in an appendix.

An important issue which has been the subject of some discussion in other papers, and which is considered further below, is the possibility that our measures of locus of control and social identity are simply proxies for other factors not included in the regression. The most discussed of these in the literature concerns the possibility that locus of control is acting as a proxy for unobserved ability ${ }^{6}$. Fortunately we are able to include a good measure of early ability in the form of the British Ability Scales. A second issue concerns the definition and role of family background. The variable employed here, parental interest in a child's education, is believed to best capture how parents influence students perceptions of the importance of education and thus strengthens their motivation to study. Variables related to familial socio-economic status such as parental social class is a candidate to be a predictor of social identity. Nevertheless as

\footnotetext{
${ }^{6}$ See, in particular, the discussions in Coleman and Deleire (2003) and Cebi (2007).
} 
Deforges and Abouchaar (2003) emphasize in their survey on the impact of parental involvement in children's education, parental interest affects school performance independently from socio-economic status. In what follows, several variables representing familial socio-economic status are employed to check the robustness of our model.

Table 2: Simple correlation coefficients amongst the explanatory variables

\begin{tabular}{|c|c|c|c|c|}
\hline & Ability & Social identity & $\begin{array}{c}\text { Personal } \\
\text { Identity }\end{array}$ & School Ethos \\
\hline Ability & 1 & - & - & - \\
\hline Social identity & .351 & 1 & - & - \\
\hline $\begin{array}{c}\text { Personal } \\
\text { Identity }\end{array}$ & .398 & .220 & 1 & 1 \\
\hline \begin{tabular}{c} 
School Ethos \\
\hline
\end{tabular} & .253 & .205 & .100 & - \\
\hline
\end{tabular}

In any event, before proceeding to the empirical analysis, initial examination check of the explanatory variables shows that whilst simple correlation coefficients are consistently positive, they nowhere exceed 0.4 (table 2). 


\section{Results}

\subsection{Base results}

The results of estimating the ordered probit model specified by equations (6) and (10) are reported in table 3 . The results show that all the explanatory variables have strong statistically significant effects on scholastic effort ( $\left.\mathrm{e}^{*}\right)$ as defined above. Ability seems to be the key determining factor, however, it is clear that both personal and social identity play a role.

Table 3: Ordered probit model of the school-leaving decision at 16 and 18.

\begin{tabular}{|l|r|r|}
\hline & Coefficient & \multicolumn{1}{|c|}{ S.E. } \\
\hline Ability $(\mathrm{n})$ & $\mathbf{0 . 7 9}^{* * * *}$ & 0.036 \\
\hline Social Identity $\left(\mathrm{I}_{\mathrm{B}}\right)$ & $\mathbf{0 . 2 6}^{* * * *}$ & 0.021 \\
\hline Personal Identity $\left(\mathrm{I}_{\mathrm{K}}\right)$ & $\mathbf{0 . 1 8}^{* * * *}$ & 0.024 \\
\hline School Ethos $(\mathrm{e}(\mathrm{S}))$ & $\mathbf{0 . 4 6}^{* * * *}$ & 0.053 \\
\hline Intercept $\left(\mathrm{a}_{0}\right)$ & $\mathbf{5 . 6 5}^{* * * *}$ & 0.018 \\
\hline Intercept $\left(\mathrm{a}_{1}\right)$ & $\mathbf{6 . 2 0}^{*} * *$ & 0.019 \\
\hline Log-Likelihood & \multicolumn{2}{|c|}{-4442.21} \\
\hline $\mathrm{n}$ & \multicolumn{2}{|c|}{5474} \\
\hline pseudo $\mathrm{R}^{2}$ & \multicolumn{2}{|c|}{0.14} \\
\hline
\end{tabular}

Note: Statistical significance indicated as follows: * indicates $\mathrm{p}<0.10, * *$ indicates $\mathrm{p}<0.05$, and $* * *$ indicates $\mathrm{p}<0.01$.

Although broadly indicative of the relative importance of the different explanatory variables, the coefficient estimates reported above tell us rather little about the impact of changes in the explanatory variables on the probability of remaining in school beyond age sixteen and eighteen. The model is non-linear so that the size of the effects of the explanatory variables on the probability of remaining in school (at either sixteen or eighteen) depends, by construction, on the base probability. In the case in hand, as is well known, the effects on the probability are greatest at the centre of the distribution ${ }^{7}$. Moreover, in the current context, the explanatory

\footnotetext{
${ }^{7}$ Specifically, it is easily verified that the marginal effects of a change in explanatory variable $X_{j}$ on the probability of interest in the univariate probit model is given by: $\beta_{j} \varphi(\mathbf{X} \boldsymbol{\beta})$, where $\varphi($.$) is the standard normal$ density function which reaches a maximum at $\Phi()=$.0.5 , where $\Phi($.$) is the standard normal distribution.$
} 
variables of interest are constructed indices ranging between the values of 1 and 5 but with differing variances, so that it is not obvious that a unit change in the explanatory variable is the appropriate basis for comparison. Rather, in Table 4, we report estimates of the effect of a one standard deviation shift in the explanatory variables on the probability of staying on at school at sixteen and eighteen. In each case the comparison is with not staying on past these ages $^{8}$. The base for the simulations here is the empirical mean probability in the sample of leaving school at sixteen and eighteen respectively.

Table 4: Effects of changes in the explanatory variables on the probability of remaining in school beyond sixteen and eighteen

\begin{tabular}{|l|c|c|c|c|}
\hline & \multicolumn{2}{|c|}{ Remaining in school at sixteen } & \multicolumn{2}{c|}{ Remaining in school at eighteen } \\
\hline & probability & Effect & probability & Effect \\
\hline Base probability & .406 & & .248 & \\
\hline + increase in: & & & & .420 \\
\hline Ability & .583 &. $\mathbf{1 8}$ & .310 & $\mathbf{. 0 8}$ \\
\hline Social Identity & .476 & $\mathbf{. 0 9}$ & .295 & $\mathbf{. 0 5}$ \\
\hline Personal Identity & .462 & $\mathbf{. 0 5}$ & .302 & $\mathbf{. 0 5}$ \\
\hline School Ethos & .470 & $\mathbf{. 0 6}$ & & \\
\hline
\end{tabular}

Note: the table reports the estimated effects on (i.e. the percentage point shift in) the probability of staying on in school arising from a variaiotn of one standard deviation in each of the explanatory variables measured at the mean probability of staying on at school at sixteen and eighteen respectively.

The reported effects modify the impression of the relative effects of different explanatory variables. In particular the effects of a shift of one s.d. in personal and social identity has roughly the same impact on the probability of staying on in school as does a similar shift in the school ethos ${ }^{9}$. One may also observe the smaller effects of all the explanatory variables on

\footnotetext{
${ }^{8}$ That is, the ordered probit is used to construct separately the estimated probabilities of remaining in school at sixteen - against leaving school at sixteen or before - and the probability of remaining in school past eighteen, against the probability of leaving school at eighteen or before.

${ }^{9}$ This is primarily because these variables, and particularly, social identity have larger variances than does the school ethos variable.
} 
the choice at eighteen compared to sixteen which arise simply because the base probability is smaller and hence further from the middle of the probability distribution ${ }^{10}$.

\subsection{Robustness checks I: separate probits}

One obvious assumption in the ordered probit estimating framework which arises as a direct consequence of the underlying theoretical model is that the effects of ability, identity and school ethos are the same for school leaving decisions both at sixteen and at eighteen. In order to examine this question, table 5 reports the results of estimating separate probit models of the school leaving decisions at 16 and 18. This serves as a first check of the robustness of our results. It is immediately clear that the coefficient estimates are extremely similar to those produced by estimation of the unified ordered probit model reported in table 2 . This is particularly true of the personal and social identity and school ethos variables which have virtually identical coefficients in both cases. However, a (statistically significant) difference emerges for the coefficient on ability which seems to play a slightly more important role at 18 than it does at $16^{11}$. One possible explanation for this arises from the (imposed) non-linearity of the estimated model. As noted above, since only around one quarter of the sample remained in education beyond eighteen, the model imposes the restriction that the effects of the explanatory variables (with constant coefficients) have a smaller percentage point impact on the probability of leaving at eighteen than they do at sixteen. As a simple check on this, a linear probability model was run on the same data. In this case the coefficient on ability remains practically unaltered - indeed it falls slightly - between 16 and 18 and the difference between the two coefficients is not statistically significant. In any event, the key results - of the important role of personal and social identity in determining the school leaving decisions at sixteen and eighteen - remain unaltered.

\footnotetext{
${ }^{10}$ This also provides a clue as to the reasons for the varying effects of ability by age considered in the analysis of robustness below.

${ }^{11}$ One might observe that this is in line with the results reported in other studies; for example, also Coleman and Deleire (2003) find that ability plays a more important role in determining attendance at college than it does for high school graduation.
} 
Table 5: Dichotomous probit models of the school-leaving decisions at 16 and 18

\begin{tabular}{|c|c|c|c|c|}
\hline & \multicolumn{2}{|c|}{ At sixteen } & \multicolumn{2}{|c|}{ At eighteen } \\
\hline & coefficient & S.E. & coefficient & S.E. \\
\hline Ability (n) & $0.74 * * *$ & 0.038 & $0.88 * * *$ & 0.043 \\
\hline Social Identity $\left(I_{B}\right)$ & $0.25^{* * * *}$ & 0.023 & $0.28 * * *$ & 0.027 \\
\hline $\begin{array}{l}\text { Personal Identity } \\
\left(\mathrm{I}_{\mathrm{K}}\right)\end{array}$ & $0.18 * * *$ & 0.026 & $0.18 * * *$ & 0.029 \\
\hline School Ethos (e(S)) & $0.45^{* * *}$ & 0.058 & $0.45^{* * * *}$ & 0.062 \\
\hline Intercept (-a) & $-5.44 * * *$ & 0.202 & $-6.56 * * *$ & 0.231 \\
\hline Log-Likelihood & \multicolumn{2}{|c|}{-3082.31} & \multicolumn{2}{|c|}{-2445.21} \\
\hline $\mathbf{N}$ & \multicolumn{2}{|c|}{5474} & \multicolumn{2}{|c|}{5474} \\
\hline pseudo $\mathbf{R}^{2}$ & \multicolumn{2}{|c|}{0.17} & \multicolumn{2}{|c|}{0.20} \\
\hline
\end{tabular}

Note: Statistical significance indicated as follows: $*$ indicates $\mathrm{p}<0.10, * *$ indicates $\mathrm{p}<0.05$, and $* * *$ indicates $\mathrm{p}<0.01$.

\subsection{Robustness checks II: Omitted variables}

One obvious possible explanation for the results is that Personal and Social identities as defined here are acting as proxies for other omitted variables which influence de facto the school-leaving decision. The most obvious of these is ability itself, which, however is already included in the estimation and, as was noted above, is positively but not strongly correlated with locus of control. However, there are other possibilities. It is well known for example, that mother's education is a strong predictor for children's academic performance ${ }^{12}$. It is not unreasonable to suppose, for example, that parental education is correlated with parental interest in their offspring's education and it is this which is being captured rather than identity per se. More generally, as noted above, it may be that it is familial socio-economic status which is captured in the estimated effects of parental interest. In order to check these possibilities, Table 6 reports the coefficients on the core explanatory variables for the model

\footnotetext{
${ }^{12}$ See, for example, Haveman and Wolfe (1995).
} 
with the inclusion of a variety of additional variables commonly introduced albeit ad hoc into more conventional human capital models of educational investment.

Table 6: Specification checks on the base model - core coefficient estimates in the presence of the inclusion of other explanatory variables

\begin{tabular}{|c|c|c|c|c|c|}
\hline & Ability (n) & $\begin{array}{c}\text { Social } \\
\text { Identity }\left(\mathrm{I}_{\mathrm{B}}\right)\end{array}$ & $\begin{array}{c}\text { Personal } \\
\text { Identity }\left(\mathrm{I}_{\mathrm{K}}\right)\end{array}$ & $\begin{array}{c}\text { School } \\
\text { Ethos }(e(S))\end{array}$ & pseudo $\mathrm{R}^{2}$ \\
\hline Base model & $.79 * * *$ & $.26 * * *$ & $.18 * * *$ & $.46 * * *$ & .14 \\
\hline $\begin{array}{l}\text { \& mother's } \\
\text { education }\end{array}$ & $.72 * * *$ & $.22 * * *$ & $.17 * * *$ & $.39 * * *$ & .16 \\
\hline $\begin{array}{l}\& \text { father's social } \\
\text { class }\end{array}$ & $.73 * * *$ & $.20 * * *$ & $.17 * * *$ & $.33^{* * *}$ & .16 \\
\hline $\begin{array}{l}\text { \& Household } \\
\text { income }\end{array}$ & $.77 * * *$ & $.23 * * *$ & $.17 * * *$ & $.36^{* * *}$ & .16 \\
\hline \& Household size & $.79 * * *$ & $.26 * * *$ & $.18 * * *$ & $.45^{* * *}$ & .14 \\
\hline $\begin{array}{l}\& \text { living with } \\
\text { natural father }\end{array}$ & $.79 * * *$ & $.26 * * *$ & $.18 * * *$ & $.46^{* * *}$ & .14 \\
\hline \& Region & $.80 * * *$ & $.26 * * *$ & $.18 * * *$ & $.47 * * *$ & .15 \\
\hline $\begin{array}{l}\& \text { BMI > 20 } \\
\text { (overweight) }\end{array}$ & $.79 * * *$ & $.26 * * *$ & $.18^{* * *}$ & $.45^{* * *}$ & .14 \\
\hline \& All together & $.70 * * *$ & $.17 * * *$ & $.16 * * *$ & $.28 * * *$ & .19 \\
\hline
\end{tabular}

Note: Each row of the table reports the coefficients on the core explanatory variables - ability, identity and school ethos, for ordered probit estimation of the school leaving decision including, one-by-one, groups of variables representing parental education, social class and so on. The last row of the table reports the results of the model including all the additional variables together.

The results suggest that, to some extent the school ethos variable is picking up the effects of other variables such as parental income, education and social class; this is also true to some extent of ability, however estimates of the effects of social and above-all personal identity remain practically unaltered by the inclusion of all these additional variables. This becomes all the more clear if we examine the estimated percentage point effects of the core variables on the probability of continuing in education beyond sixteen and eighteen shown in table 7 . The table compares the estimated effects of the four core explanatory variables employing the specifications reported in the first and last rows of table 6; that is, comparing the base 
specification with that including a full set of additional explanatory variables. As can be observed, inclusion of these variables leads to a fall in the estimated impact of 3 percentage points for parental interest (social identity), 2 percentage points for ability, 1-2 percentage points for school ethos and zero or one percentage point for locus of control. Thus the estimates are rather robust to the inclusion of a range of other explanatory variables. Certainly, even with the inclusion of these variables, the role of social and personal identity remains strong and statistically significant.

Table 7: Effects of changes in the main explanatory variables on the probability of remaining in school beyond sixteen and eighteen, without and with additional explanatory variables

\begin{tabular}{|l|c|c|c|c|}
\hline & \multicolumn{2}{|c|}{ Remaining in school at sixteen } & \multicolumn{2}{c|}{ Remaining in school at eighteen } \\
\hline & $\begin{array}{c}\text { Effect using } \\
\text { parsimonious } \\
\text { specification }\end{array}$ & $\begin{array}{c}\text { Effect using } \\
\text { full } \\
\text { specification }\end{array}$ & $\begin{array}{c}\text { Effect using } \\
\text { parsimonious } \\
\text { specification }\end{array}$ & $\begin{array}{c}\text { Effect using } \\
\text { full } \\
\text { specification }\end{array}$ \\
\hline Ability & .18 & .16 & .17 & .15 \\
\hline Social Identity & .09 & .06 & .08 & .05 \\
\hline Personal Identity & .05 & .05 & .05 & .04 \\
\hline School Ethos & .06 & .04 & .05 & .03 \\
\hline
\end{tabular}

Note: the table reports the estimated effects on the probability of staying on in school at sixteen of a shift of one standard deviation in each of the explanatory variables measured at the mean probability of staying on at school at sixteen and eighteen respectively. 


\section{Concluding remarks}

In this paper we have developed and estimated a model of educational investment which takes into account the central role played by both personal and social identity in shaping schooling choices. We find that both social and personal identity have substantial and statistically significant effects on educational participation decisions and these impacts are robust to a variety of specification and potentially confounding factors.

The key implication is that educational choice is not purely a matter of rational economic calculus concerning the net wage returns to education as posited by the human capital model, nor is it simply a matter of social conditioning dependent on the social class of origin. Rather the choice problem here also includes socio-psychological aspects which have a direct influence on the utility derived from studying. In our view, values stressing the importance of educational achievements transmitted by family - social identity - and internal locus personal identity - play a crucial role in motivating school effort, which generally in the literature causes only disutility. Whereas in our case, these socio-psychological factors determine the utility from effort, thus determining individual choices. Accordingly children who have internalized familial values emphasizing school importance, derive utility from effort by meeting their parents' expectations and children with internal locus are more motivated at school as they have a stronger feeling of control of success and failure deriving from their sense of competence about their abilities.

We find moreover that social identity plays a rather more important role than personal identity in influencing the probability of staying on at school. Noting also that locus of control is related to individuals' inner selves and is consequently relatively impermeable to outside influences, one implication of our results is that factors that increase parental interest in their offspring's education may compensate the lack of internal locus in individuals.

The logical coherence of the theoretical model, its close relation with its empirical counterpart and the closeness of the underlying theoretical concepts and their empirical realizations, along 
with the robustness to a variety of specifications of the results leaves us confident that our results may contribute to a deeper understanding of children's performance at school. 


\section{REFERENCES}

Abdallah, T. M. (1989). Self-Esteem and Loss of Control of College Men in Saudi Arabia, Psychological Reports, 65, pp.1323-26.

Akerlof, G. A., Kranton, R. E. (2000). Economics of Identity, The Quarterly Journal of Economics, vol. 115, no. 3, pp.715 - 753 .

Akerlof, G. A., Kranton, R. E. (2002). Identity and Schooling: Some Lessons for the Economics of Education, Journal of Economic Literature, vol. 40, no. 4, pp. 1167 - 1201.

Akerlof, G. A., Kranton, R. E. (2005). Identity and the Economics of Organizations, The Journal of Economic Perspectives, vol. 19, no. 1, pp. 9 - 32.

Andrisani, P. J. (1977). Internal-External Attitudes, Personal Initiative, and Labor Market Experience of Black and White Men, Journal of Human Resources, vol. 12, no. 3, pp. 308328.

Baumeister, R. F., Campbell, J. D., Krueger, J. I., Vohs, D. (2003). Does high self-esteem cause better performance, interpersonal success, happiness, or healthier lifestyles?

Psychological Science in the Public Interest, vol. 4, n.1, pp. 1-44.

Barón, J. D., Cobb-Clark, D. (2010). Are Young People's Educational Outcomes Linked to their Sense of Control? IZA Discussion Paper no. 4907.

Bowles, S., Gintis, H., Osborne, M. (2001). The Determinants of Earnings: a Behavioral Approach, Journal of Economic Literature, vol.39, no. 4, pp. 1137-1176.

Coleman, J. S. (1988). Social Capital in the creation of human capital, American Journal of Sociology, vol. 94, pp. S95 - S120.

Coleman, M., DeLeire, T. (2003). An economic model of locus of control and the human capital investment decision, Journal of Human Resources, Vol.38, no. 3, pp. 701-721.

Haußer, K. (1995). Identitatspsychologie [Psychology of identity]. Berlin: Springer-Verlag.

Haveman R, Wolfe B. The determinants of children's attainments: A review of methods and findings. Journal of Economic Literature. 1995, vol. 33, pp.1829-1878.

Heckman, J. J., Stixrud, J., Urzua, S. (2006) The effects of cognitive and noncognitive abilities on labor market outcomes and social behavior. NBER Working Paper no. 12006.

Hill, V. (2005). Through the Past Darkly: A Review of the British Ability Scales Second Edition, Child and Adolescent Mental Health, Vol. 10, no. 2, pp. 87-98.

Horst, U., Kirman, A., Teschl, M. (2006). Changing identity: the emergence of social groups, GREQAM, n. $2006-51$, pp.1-34.

Jones, S. R., McEwen, M. K. (2000). A Conceptual Model of Multiple Dimensions of 
Identity, Journal of College Student Development, Vol. 41 n. 4, pp. 405-414.

Judge, T. A., Bono, J. E. (2001). Relationship of Core Self-Evaluations Traits-Self-Esteem, Generalized Self-Efficacy, Locus of Control, and Emotional Stability-With Job Satisfaction and Job Performance: A Meta-Analysis, Journal of Applied Psychology, vol. 86, n.1, pp.8092.

Kelman, H. C. (2006). Interests, relationships, identities: Three central issues for individuals and groups in negotiating their social environments, Annual Review of Psychology, vol. 57, pp. $1-26$.

Osborne, M. (2005). How important is your personality? Labor market returns to personality for women in the US and UK, Journal of Economic Psychology, vol. 26, pp. 827-841.

Pearlin, L. I., \& Kohn, M. L. (1966). Social class, occupation, and parental values: A crossnational study, American Sociological Review, 31, 466-479.

Postmes, T., Baray, G., Haslam, S. A., Morton, T., Swaab, R. (2006). The dynamics of personal and social identity formation, in T. Postmes, J. Jetten (eds.), Individuality and the group, advances in social identity, London: Sage.

Rotter, J. B. (1966). Generalized Expectancies for Internal versus External Control of Reinforcement, Psychological Monographs, 80 (Whole no. 609).

Von Stumm, S., Gale, C. R., Batty, G. D., Deary, I. J. (2009). Childhood intelligence, locus of control and behaviour disturbance as determinants of intergenerational social mobility: British Cohort Study 1970, Intelligence, 37, pp. 329-340.

Wang, L., Kick, E., Fraser, J., \& Burns, T. J. (1999). Status attainment in America: The roles of locus of control and self-esteem in educational and occupational outcomes. Sociological Spectrum, 19, 281-298. 